1606b ENVIRONMENTAL SAMPLING AND HUMAN BIOMONITORING FOR HAZARDOUS DRUGS: IMPLICATIONS FOR WORKER HEALTH AND RISK OF HARM

MA McDiarmid. University of Maryland School of Medicine, Baltimore, Maryland, USA

\subsection{6/oemed-2018-ICOHabstracts.936}

The DNA damaging effects of treatment with hazardous, anticancer drugs (HD) resulting in therapy- related leukaemia and other cancers have been recognised for more than thirty years. Health concerns for cancer caregivers handling these drugs has also been raised as scores of environmental monitoring studies documented drug contaminated work areas including some linking these results to drug levels in workers' urine, documenting drug uptake. Biomarkers of cytogenetic effect have also been examined, including chromosomal damage and micronuclei frequency, both of which may be prognostic of an increased cancer risk, suggesting they are potentially meaningful markers of effect. Importantly, dose-related excesses in 'signature' chromosomal aberrations typically seen in patients treated with specific anti-cancer drug classes have recently been reported in workers, even while 'using' safe handling practices.

Beyond the cancer risk, acute effects such as skin disorders and respiratory compromise from allergic sensitisation have also long been described in workers, as has reproductive loss, reflecting the experience of treated patients and the drugs' known mechanisms of action. Of the 184 drugs on the 2014 NIOSH HD list, about $80 \%$ are classified as harmful to reproduction. In the most recent large, epidemiology study on this topic, investigators found a statistically significant two-fold increased risk of spontaneous abortion in nurses reporting first-trimester HD exposure.

While safe drug handling practices have been promoted since the 1980s, concern has persisted that the risk has not been fully addressed. The findings above amplify that concern and suggest that biologically important exposure and health risks persist for oncology workers. This presentation will review the evidence documenting hazardous drug exposure and will argue the need to enforce safe handling as the standard of practice in clinical oncology.

\section{C THE PRESENT AND FUTURE NEED OF CLOSED SYSTEM TRANSFER DEVICES (CSTD)}

Marc A Levy. Institute of occupational and environmental medicine, Rambam Medical Campus, Haifa, Israel

\subsection{6/oemed-2018-ICOHabstracts.937}

For decades health care workers (HCWs) have dedicated themselves in order to improve their knowledge and understanding of diseases and their treatments in order to help their patients. At times, they have donated their bodies and caused harm to their health, when using new technologies or drugs with unknown side effects, as did Marie Curie when she was researching treatment with radium.

Antineoplastic drugs are largely used in the world today and, because of their activity, there is much concern about the exposure to health care workers during preparation, distribution and administration to the patient. Many studies have clearly proven contamination of preparation surfaces and absorption, metabolism and excretion of these chemicals in HCWs.

Many other studies have shown severe health hazards on HCWs including chromosomal defects.

In the last year, closed systems (CSTD) were developed in order to avoid exposure and protect HCWs from contamination. We will present a few of the existing and future closed systems. We will also address and the implication of new fields like immunotherapy, biological treatments and nanoparticles.

\section{$1606 \mathrm{~d}$ REPORT OF TASK FORCE ON HANDLING HAZARDOUS DRUGS}

Rosa Orriols. Task Force for Handling Hazardous Drugs - Scohhcw

\subsection{6/oemed-2018-ICOHabstracts.938}

Every year millions of Health Care Workers (HCWs) are exposed to carcinogenic, mutagenic and repro-toxic hazardous drugs, and in particular, cytotoxic drugs. These drugs represent the most dangerous chemical risk factors in healthcare and some of the most hazardous chemicals ever developed. The workplace exposure to dangerous drugs and the resulting health risks for healthcare personnel are well known yet, adequate education and training in handling hazardous drugs is both under appreciated and inadequate in many health care facilities. The SCOHHCW established a Task Force on Handling Hazardous Drugs in 2017 to address these issues. This session will report on the progress of this Task Force to date.

\section{INFECTIOUS RISKS IN PROVIDING HEALTH CARE: PREPARE FOR THE UNEXPECTED}

Gwen Brachman*. Secretary SC OH HCW, ICOH

\subsection{6/oemed-2018-ICOHabstracts.939}

Aim Discuss procedures for evaluation, responses, and treatment of occupational infectious diseases in health care facilities and health care workers.

Presenters: ${ }^{1} \mathrm{G}$ De Carli, ${ }^{2} \mathrm{~B}$ Hayes, ${ }^{3} \mathrm{~L}$ Mazon, ${ }^{4} \mathrm{C}$ Rapparini

${ }^{1}$ National Institute for Infectious Diseases L. Spallanzani IRCCS, Rome, Italy

${ }^{2}$ Occupational Health Department, Beaumont Hospital, Dublin, Ireland

${ }^{3}$ Occupational Health Service, Hosital Universitario Fuenlabrada, Madrid, Spain

${ }^{4}$ Riscobiologico.org Network, Rio de Janeiro, Brazil

\section{1 a LEARNING FROM EXPERIENCE: IDENTIFICATION OF RISKS AND CONTROL MEASURES}

G De Carli. National Institute for Infectious Diseases L. Spallanzani-IRCCS, Rome, Italy

10.1136/oemed-2018-ICOHabstracts.940

The protection of healthcare workers (HCWs) from occupational infections developed in parallel with that of patients from healthcare-associated infections. In 1915, Richardson wrote that nurses avoided the care of patients with infectious 